\title{
Socio-Emotional and Cognitive Resilience in Children with Reading Disabilities
}

Stephanie L. Haft 1, Chelsea A. Myers 1, Fumiko Hoeft 1,2,3,*

${ }^{1}$ Department of Psychiatry, University of California, San Francisco, Box 0984, San

Francisco, CA 94143, USA

${ }^{2}$ Haskins Laboratories, 300 George St \#900, New Haven, CT 06511, USA

${ }^{3}$ Department of Neuropsychiatry, Keio University School of Medicine, 35 Shinanomachi

Shinjuku-ku, Tokyo, 160-8582 Japan

* Correspondence:

Fumiko Hoeft MD PhD

Address: 401 Parnassus Ave, San Francisco, CA 94143

Phone: +1 415476 9861, Email: Fumiko.Hoeft@ucsf.edu 


\begin{abstract}
In recent times, research on resilience in children facing adversities has proliferated. In this review, the authors characterize resilience in children with reading disorders (RD). To organize our discussion and categorize the specific outcomes such children demonstrate, we adopt the terms cognitive resilience and socio-emotional resilience. By paralleling other resilience research, we seek to uncover protective factors in the hopes that they can be targeted in education and interventions to improve cognitive functioning, socio-emotional wellbeing, and academic success of children with RD. We conclude by considering current limitations and addressing the need for future resilience research in this specific population of children.
\end{abstract}

\title{
ACKNOWLEDGMENT
}

FH was supported by the Eunice Kennedy Shriver National Institute of Child Health and Human Development (NICHD) Grants K23HD054720, R01HD078351, R01HD044073 (PI: L. Cutting, Vanderbilt U), R01HD065794 (PI: K. Pugh, Haskins Labs), P01HD001994 (PI: J. Rueckl, Haskins Labs), the National Institute of Mental Health (NIMH) Grants R01MH104438 (PI: C. Wu Nordahl, UC Davis MIND Institute), R01MH103371 (PI: D. Amaral, UC Davis MIND Institute), the National Science Foundation (NSF) Grant NSF1540854 SL-CN (PI: A. Gazzaley), UCSF Dyslexia Center, UCSF Academic Senate Award, UCSF-CCC Neuroscience Fellowship (\& Liebe Patterson), and Dennis \& Shannon Wong - DSEA '88 Foundation. 


\section{INTRODUCTION}

Approximately $7 \%$ of children have specific difficulties in learning to read (developmental dyslexia, decoding-based reading disability or reading disorder; from here on $\mathrm{RD} ;[1,2]) . \mathrm{RD}$ is a polygenic disorder characterized by deficits in rapid automatized naming (RAN; [3,4] verbal short-term memory [5,6], and most notably phonological awareness (PA; [7-9]). These deficits not only lead to poor decoding [10], but most often result in downstream effects on spelling [11,12], vocabulary [13], and reading comprehension $[14,15]$. As a result, students may experience academic failure and are 2.5 times more likely to drop out of high school [16]. With increased risk for and experiences of failure in school, as well as greater likelihood of peer rejection [17], students with RD are susceptible to significant socio-emotional consequences [18], which could in turn lead to further reduction in academic performance [19,20].

Despite these academic risks and negative cognitive and socio-emotional consequences, many individuals with RD demonstrate positive trajectories and grow up to lead successful lives. This begs the question: which factors encourage resilience and ultimately success in some individuals with RD?

\section{PRESENT REVIEW}

Traditionally, resilience has been defined as the trajectory from the presence of significant risk or adversity to achievement of positive adaptation or outcomes [21]. The present review applies the concept of resilience to children with or at-risk for developing $\mathrm{RD}$, focusing primarily on protective factors that positively modify or alter the effects of risks and outcomes of children with RD. For details on etiological risk factors for RD and their mechanisms, readers are referred to Vandermosten Hoeft and Norton (2016) and Ozernov-Palchik, Yu, Wang and Gaab (2016) in the current issue. The focus on resilience and protective factors is timely as the field shifts toward a multifactorial theory of RD, that both risk and protective factors interacting at the genetic, neural, cognitive, and environmental levels contribute to the overall functional outcome of RD [22]. To provide a non-exhaustive qualitative review of the literature relevant to cognitive resilience and socio-emotional resilience of $\mathrm{RD}$, operationalized in their respective sections, we used search terms relevant to resilience in RD and dyslexia (e.g. "protective," "compensation," 
"resilience," "unimpaired," "support," “adjustment," “environment," "strength,”) with a focus on recent articles involving children and adolescents.

\section{COGNITIVE RESILIENCE}

While there are numerous studies that define "resilience," there are currently few studies that operationalize "cognitive resilience." A PubMed search of cognitive resilience, for example, shows that most of the dozen peer-reviewed studies utilizing the term do so in reference to aging and related disorders, defining it as preserved cognitive function despite evident neuropathology (such as mid-frontal lesions and neurofibrillary tangles) [23] or significant genetic risk (from presence of apolipoprotein E $\epsilon 4$ allele) [24]. Within this framework, individuals who display cognitive resilience may be considered as those with neurobiological risk factors for RD (such as presence of risk genes for RD, a family history of RD, or phonological processing deficits; see also Vandermosten Hoeft Norton (2016) and Ozernov-Palchik, Yu, Wang and Gaab (2016) in current issue) who never develop, or only develop mild deficits of the core phenotype, such as difficulties with decoding words. We may also refer to those with RD who display core characteristic deficits of RD but who show milder downstream effects such as reading comprehension deficits as displaying cognitive resilience. In this section, we will discuss the protective factors that may enable cognitive resilience.

Studies examining characteristics of at-risk pre-readers who never develop later reading problems provide important clues for mechanisms of cognitive resilience in children with RD (Table 1a). A study by Gallagher et al. [25] showed that at-risk prereaders who were unimpaired on reading measures at school-age performed higher than their at-risk impaired counterparts on early measures of oral language tests - later studies showed similar results [26,27]. Strengths in expressive language in children at familial risk for dyslexia who never develop the disorder is observed as young as 2 years old [28]. Some authors have suggested that the mechanism of resilience for these children is the use of language skills and semantic context to circumvent phonological decoding deficits - known as "semantic bootstrapping" [29]. Executive function (EF) may also be another mechanism through which children display cognitive resilience. For example, a recent study showed that poor EF in preschool is a predictor of later $\mathrm{RD}$, and that strengths in 
EF had more significant positive effects "when a child showed poor performance on the core predictors of dyslexia, suggesting good $[\mathrm{EF}]$ provides some compensation for the impact of low 'readiness' for learning to read [30]." Another study found that high levels of task-focused behavior - often referred to as internal goal-driven, top-down or endogenous attention - is what distinguished children with familial risk of RD who never developed it from those at-risk who were later diagnosed [31] - empirical research should further explore the process in which these types of attention impact reading outcome. Finally, strengths in some types of early fine motor skills may also be important for later reading outcome [32]. While the mechanism is unknown, it is intriguing that fine motor skill tasks such as hand-writing have been shown to rely on brain regions also relevant to reading in beginning readers [33].

Mechanisms of cognitive resilience may also be inferred from studies of children who develop RD but who do not show the typical downstream effects such as weakness in reading comprehension arising from phonological and decoding deficits, otherwise known as resilient readers [34] (Table 1b). Resilient readers may rely more on contextual information to be able to read successfully [35] - this is in line with Stanovich's [36] "Interactive compensatory model of dyslexia". One study of "compensated" dyslexic university students - where "compensated" is defined as those achieving higher than expected literacy in light of phonological deficits - showed that students' strengths in morphological awareness were associated with improved reading outcome [37]. Other studies have similarly found that children with RD can rely on morphological structure to decode words faster, despite decoding difficulties [38,39]. Vocabulary skills have also been implicated as a compensatory mechanism for college students with RD [40], and have been shown to mediate between impaired verbal working memory and oral reading fluency in adolescents with RD [41]. More superior verbal reasoning skills in general have been shown to explain higher reading, spelling, morphological, and syntactic skills in students with RD [42]. As is the case in at-risk pre-readers, this implies that resilient readers may use contextual cues or "semantic bootstrapping" in order to process written text. EF may also play an important role for compensated or resilient readers - strong working memory in particular may circumvent reading problems in dyslexic children [43]. Cognitive flexibility, another EF component, is found to be crucial for core 
components of reading comprehension in low-risk readers, and may also be important for those with RD [44]. A neuroimaging study showed that greater right prefrontal activation during a reading task - an area associated with EF [45] - is correlated with future gains in reading comprehension in children with RD [46] (see Hancock, Richland, and Hoeft, under review, for more on frontostriatal hyperactivation in RD and proposed compensatory roles). This was the case despite lack of systematic interventions in these children, which may infer its relevance to cognitive resilience.

In addition to cognitive factors, environmental factors may contribute to cognitive resilience. For example, a study of children with RD showed that the effect of RD on reading fluency was mediated by support from teachers and peers with a cumulative effect [47] - the contribution of interpersonal protective factors will be discussed more in the section on socio-emotional resilience.

In summary, oral language skills (e.g. vocabulary) appear to be critical for cognitive resilience in children at-risk for and with a diagnosis of RD. Other language skills such as morphological awareness also appear to be important factors that promote cognitive resilience. Neurologically, prefrontal and related networks that underlie these processes may be involved. However, more research is warranted on the mechanisms underlying brain-behavior relationship regarding protective factors, compensatory mechanisms in RD, and in particular, prevention of RD in children at-risk for developing RD.

\section{SOCIO-EMOTIONAL RESILIENCE}

In addition to cognitive resilience, students with RD can exhibit socio-emotional resilience, or positive psychosocial adjustment despite risk presented by RD. In the transactional nature of the resilience framework, $\mathrm{RD}$ can be seen as influencing a child at the individual, family, and community level - these factors can in turn be protective and counterbalance the risk presented by $\mathrm{RD}$, thereby promoting resilience. In this section we will discuss the risks to socio-emotional well-being children with RD face, and how despite these challenges children with RD can exhibit resilience and maintain positive internal concepts and relationships. 
Studies have shown that the presence of RD acts as a risk factor for socioemotional maladjustment. One proposed mechanism underlying this relationship is that socio-emotional functioning issues co-occur with RD, potentially because of deficits in information-processing and impulsivity ("primary-cause hypothesis"; [48,49]. Another viewpoint is that socio-emotional problems arise as a secondary emotional reaction from the stress of repeated reading failure ("secondary-cause hypothesis"; [48,50]. Regardless, the literature is clear that students with RD are more likely than their typically developing peers to have low self-esteem, face peer rejection, and become anxious or depressed [18,51]-additional comorbidities [52,53], low socio-economic status or social support $[18,54]$, as well as being a female [49,51], typically exacerbate these negative outcomes. This can result in a vicious cycle whereby negative emotions and social experiences reciprocally interact with a child's $\mathrm{RD}$, limiting cognitive capacity and sustaining reading failure $[19,20]$.

Several individual attributes may contribute to socio-emotional resilience and academic achievement of those with RD. Early longitudinal studies implicated selfawareness, proactivity, perseverance, realistic educational plans, and appropriate goal setting in promoting resilience for well-adapted adults with RD/LD (Learning Disabilities) [55-57]. More recently, a pre- and post- study of a program for middle school students with RD showed that increases in locus of control were associated with more adaptive coping strategies, increased school engagement, and overall well-being [58]. Other studies have linked sense of coherence (an index of sense of control and resources; [59]) and self-determination (viewing oneself as a causal agent; [60]) to positive socio-emotional and academic adjustment in students with RD and other LDs. In other words, it appears that a greater sense of control is important for students to cope effectively with the difficulties that their RD presents - this concurs with an early retrospective study of highly successful adults with $\mathrm{RD} / \mathrm{LD}$, where the dominant factor implicated in success was the individual's ability to take control of his or her life $[61,62]$. In addition, hope was found to mediate between risk and protective factors for students with RD/LD in one study, resulting in greater academic self-efficacy and effort investment [63] - this may be because hopeful thinking involves goal-oriented thoughts, which may help in coping with academic and social barriers [63-65]. 
Growth mindset, an individual's belief that his or her intelligence is malleable (e.g. an incremental theory of intelligence), as opposed to a fixed mindset where one believes one's intelligence cannot be further developed (e.g. entity theory of intelligence), is associated with increased resilience in children [66], and has been shown to buffer against demotivation that results from academic difficulties [67]. Baird et al. [68] found that maladaptive goal orientation and effort attributions in youth with $\mathrm{RD} / \mathrm{LD}$ are linked directly to their entity theories of intelligence. These findings suggest that if youth with $\mathrm{RD}$ would adopt a growth mindset, they would be less likely to perceive the exertion of effort as indicative of low ability, and may instead persevere through reading challenges and subsequently perform higher. In line with this, one neuroimaging study has shown that growth compared to fixed mindset leads to stronger coupling between attention allocation and post-error performance during an attention and inhibitory control task, presumably in the anterior cingulate cortex, part of the medial prefrontal region (flanker task; [69]). In other words, those who adopt a growth mindset show a more adaptive brain-behavior connection in adjusting to errors - this is important for students with RD, as they may be better able to adjust their performance on academic tasks when given feedback on their weaknesses and errors.

The aforementioned individual attributes can be fostered or bolstered by familylevel factors. Family cohesion partially explained hopeful thinking in a group of students with RD/LD [63]. Children [70,71] and adults [72] with RD who have strong relationships with their parents, and whose parents had a good understanding of their RD [71], are found to have higher self-esteem than those with weaker parental relationships. Al-Yagon has suggested unique roles for mothers and fathers in this socio-emotional resilience. Strong attachment to fathers is associated with more sense of coherence, hope, and effort in children with $\mathrm{RD}$, while attachment to mothers has been found to protect against loneliness and internalizing symptoms such as anxiety [73,74].

Peers may also play a protective support role outside the home. A recent study showed that a high quality relationship with a best friend contributed significantly to lower internalizing and externalizing issues in adolescents with learning disabilities (LD) including RD [74]. Similarly, having stable and close friendships was found to be a protective factor for university students with $\mathrm{RD} / \mathrm{LD}$, predicting greater global self-worth 
and social self-concept [75]. A large body of literature confirms the relationship between peer support and acceptance, and positive socio-emotional outcomes in children unfortunately, work in the RD population specifically focuses mainly on peers as threats [70].

Teachers are in a role to foster a classroom environment that promotes socioemotional resilience - analysis of a nationally representative sample showed that mentorship by teachers was associated with self-esteem differences in youth with RD/LD compared to nonmentored youth [76]. Additionally, supportive teachers can effectively protect children against negative impacts of peer rejection due to their RD, controlling for other risk variables [17]. Perceptions of teachers as caring and available are also important in promoting positive affect for RD students [74]. Though a thorough discussion comparing special education vs. mainstream educational settings for children with RD is beyond the scope of this review, studies suggest that children with RD have higher self-esteem when they are in smaller classrooms [17].

Attachments to others may increase socio-emotional resilience for children with RD by providing a "secure base [77]" where children can then direct energy and attention toward exploring their environment and acquiring skills needed for reading. Related to this is "stress and coping theory," the belief that when social support is perceived as available, individuals are able to reframe negative experiences and engage in productive coping skills [78]. Although such social support theories are valuable in explaining potential mechanisms underlying socio-emotional resilience, more work should be done to understand how they function specifically for children with RD.

In summary, attributes such as sense of control, growth mindset, and hopeful thinking, as well as strong interpersonal relationships and supportive classroom contexts can foster socio-emotional resilience in children with RD (see Table 2). Neurobiological correlates and well-controlled studies with more quantitative measures lag in comparison to cognitive studies in RD, and is a suggested area of growth in the field.

\section{CONCLUSION}

Our findings suggest that while some children have etiological risk factors that confer risk for $\mathrm{RD}$, cognitive and socio-emotional protective factors may reduce the 
severity of RD symptoms and individual outcome through several strategies and mechanisms identified in this review. These protective factors that lead to cognitive and socio-emotional resilience likely influence reading outcome in a reciprocal manner (though empirical evidence is lacking), and together contribute to an individual's capacity to adapt to adversity. With regards to interventions, it appears that it is not only necessary to focus on and foster skills directly related to reading (e.g. PA) in pre- and beginning readers, but also to focus on honing oral language skills and EFs early. In examining literature related to resilient or compensated readers, it seems that utilizing cognitive strengths (e.g. semantic contextual clues) to offset potential core deficits can improve reading outcome [34-36], as well as building on the confidence and optimism of those with RD. Children with RD should be made to feel like they are in control of their lives and academic outcomes. Fostering a growth mindset is also particularly important given the academic difficulties children with RD face - this can be done by praising perseverance and effort [79].

Several limitations of this review should be acknowledged. First, we operationalize the term cognitive resilience based off of its use in aging and dementia literature. To our knowledge, the literature discussing RD does not use this specific terminology. Second, we discuss some protective factors that are not typically considered etiological risk factors for RD (e.g. motor skills, executive functions), but if further research indicates that they are, then their role as protective (and not merely absence of risk) should be reconsidered. One way to investigate this is to examine the extent of impairment in those at-risk for RD in these areas, or whether those which above-expected reading outcome show enhancement of these skills. Third, we discuss preserved selfesteem and self-efficacy as positive features for children with RD, but it should be noted that an overly positive estimation of one's abilities, or positive illusory bias, has been documented in children with LD and can be detrimental [80]. Future research should focus more on this potential issue, as well as on the importance of realistic competency assessment and its relation to self-esteem and performance in children with RD. Third, much of the literature involving children with RD focuses disproportionately on risk factors and negative outcomes. Certainly more work with a focus on factors that promote positive outcomes in children with RD is needed, specifically on mechanisms of 
resilience rather than merely identifying protective antecedent variables. Finally, due to space constraints, we recommend other reviews such as the following for neurobiological mechanisms underlying resilience $[81,82]$, as they are not discussed here.

To our knowledge, this paper represents one of the only recent reviews investigating resilience within the population of children with or at-risk for RD. Emphasizing contributors to resilience for students with or at-risk for RD bolsters our understanding of best practices for these children that may not be achieved with deficitfocused models. Such knowledge will contribute to higher reading and academic performance in these children, allowing them to grow into competent and successful adults. 


\section{References}

1. Capital FM: Wellbeing Project (2008) Final Project Report. The Government Office for Science; 2008.

2. Goswami U: Sensory theories of developmental dyslexia: three challenges for research. Nat. Rev. Neurosci. 2015, 16:43-54.

3. Norton E, Wolf M: Rapid Automatized Naming (RAN) and Reading Fluency: Implications for Understanding and Treatment of Reading Disabilities. Апnи. Rev. Psychol. 2012, 63:427-452.

4. De Groot BJA, Van den Bos KP, Van der Meulen BF, Minnaert AEMG: Rapid Naming and Phonemic Awareness in Children With or Without Reading Disabilities and/or ADHD. J. Learn. Disabil. 2015, doi:10.1177/0022219415609186.

5. Siegel LS, Ryan EB: Development of Grammatical-Sensitivity, Phonological, and Short-Term Memory Skills in Normally Achieving and Learning Disabled Children. Dev. Psychol. 1988, 24:28-37.

6. Laasonen M, Virsu V, Oinonen S, Sandbacka M, Salakari A, Service E:

Phonological and sensory short-term memory are correlates and both affected in developmental dyslexia. Read. Writ. 2012, 25:2247-2273.

7. Bradley L, Bryant PE: Difficulties in auditory organisation as a possible cause of reading backwardness. Nature 1978, 271:746-747.

8. Kovelman I, Norton ES, Christodoulou JA, Gaab N, Liberman DA, Triantafyllou C, Wolf M, Whitfield-Gabrieli S, Gabrieli JDE: Brain Basis of Phonological Awareness for Spoken Language in Children and Its Disruption in Dyslexia. Cereb. Cortex 2012, 22:754-764.

9. Dandache S, Wouters J, Ghesquiere P: Development of reading and phonological skills of children at family risk for dyslexia: A longitudinal analysis from kindergarten to sixth grade. Dyslexia 2014, 20:305-329.

10. Gough PB, Tunmer WE: Decoding, Reading, and Reading Disability. Remedial Spec. Educ. 1986, 7:6-10.

11. Bruck M: Component spelling skills of college students with childhood diagnoses of dyslexia. Learn. Disabil. Q. 1993, 16:171-184.

12. Lefly D, Pennington B: Spelling errors and reading fluency in dyslexics. Ann. Dyslexia 1991, 41:143-162.

13. Vellutino FR: Dyslexia. Sci. Am. 1987, 256:34-41. 
14. Garcia JR, Cain K: Decoding and Reading Comprehension: A Meta-Analysis to Identify Which Reader and Assessment Characteristics Influence the Strength of the Relationship in English. Rev. Educ. Res. 2014, 84:74-111.

15. Kjeldsen A-C, Karna A, Niemi P, Olofsson A, Witting K: Gains From Training in Phonological Awareness in Kindergarten Predict Reading Comprehension in Grade 9. Sci. Stud. Read. 2014, 18:452-467.

16. IDEAdata.org: Exiting by Disability, Ages 14-21. Individuals with Disabilities Education Act (IDEA); 2002.

17. Kiuru N, Poikkeus A-M, Lerkkanen M-K, Pakarinen E, Siekkinen M, Ahonen T, Nurmi J-E: Teacher-perceived supportive classroom climate protects against detrimental impact of reading disability risk on peer rejection. Learn. Instr. 2012, 22:331-339.

18. Mugnaini D, Lassi S, La Malfa G, Albertini G: Internalizing correlates of dyslexia. World J. Pediatr. 2009, 5:255-264.

19. Morgan PL, Farkas G, Wu Q: Do poor readers feel angry, sad, and unpopular? Sci. Stud. Read. 2012, 16:360-381.

20. Stanovich KE: Matthew effects in reading: Some consequences of individual differences in the acquisition of literacy. Read. Res. Q. 1986, [no volume].

21. Masten AS: Global Perspectives on Resilience in Children and Youth. Child Dev. 2014, 85:6-20.

22. Pennington BF: From single to multiple deficit models of developmental disorders. Cognition 2006, 101:385-413.

23. Arnold SE, Louneva N, Cao K, Wang L-S, Han L-Y, Wolk DA, Negash S, Leurgans SE, Schneider JA, Buchman AS, et al.: Cellular, synaptic, and biochemical features of resilient cognition in Alzheimer's disease. Neurobiol. Aging 2013, 34:157-168.

24. Barnes LL, Bennett DA: Cognitive resilience in $\mathrm{APOE} * \boldsymbol{\varepsilon} 4$ carriers-is race important? Nat. Rev. Neurol. 2015, 11:190-191.

25. Gallagher A, Frith U, Snowling MJ: Precursors of Literacy Delay among Children at Genetic Risk of Dyslexia. J. Child Psychol. Psychiatry 2000, 41:203213.

26. Carroll JM, Mundy IR, Cunningham AJ: The roles of family history of dyslexia, language, speech production and phonological processing in predicting literacy progress. Dev. Sci. 2014, 17:727-742. 
27. Hulme C, Nash HM, Gooch D, Lervag A, Snowling MJ: The Foundations of Literacy Development in Children at Familial Risk of Dyslexia. Psychol. Sci. 2015, [no volume].

28. Torppa M, Lyytinen P, Erskine J, Eklund K, Lyytinen H: Language Development, Literacy Skills, and Predictive Connections to Reading in Finnish Children With and Without Familial Risk for Dyslexia. J. Learn. Disabil. 2010, 43:1-14.

29. Muter V, Snowling MJ: Children at Familial Risk of Dyslexia: Practical Implications from an At-Risk Study. Child Adolesc. Ment. Health 2009, 14:3741.

30. Thompson PA, Hulme C, Nash HM, Gooch D, Hayiou-Thomas E, Snowling MJ: Developmental dyslexia: predicting individual risk. J. Child Psychol. Psychiatry 2015, 56:976-987.

** This study extends the work of previous studies by providing insight into when certain predictors of dyslexia may be more salient for screening purposes. Moreover, the authors included measures of executive function and fine motor skills, which provide a more comprehensive analysis.

31. Eklund KM, Torppa $\mathrm{M}$, Lyytinen $\mathrm{H}$ : Predicting reading disability: early cognitive risk and protective factors. Dyslexia 2013, 19:1-10.

*This study is valuable in its longitudinal design of RD trajectory, and examining how task avoidance may function as a protective factor. This work is a great example of extending research to how non-reading skills may affect RD outcome.

32. Gooch D, Hulme C, Nash HM, Snowling MJ: Comorbidities in preschool children at family risk of dyslexia. J. Child Psychol. Psychiatry 2014, 55:237246.

33. Gimenez P, Bugescu N, Black JM, Hancock R, Pugh K, Nagamine M, Kutner E, Mazaika P, Hendren R, McCandliss BD, et al.: Neuroimaging correlates of handwriting quality as children learn to read and write. Front. Hum. Neurosci. 2014, 8:155.

34. Welcome SE, Chiarello C, Halderman LK, Leonard CM: Lexical processing skill in college-age resilient readers. Read. Writ. 2009, 22:353-371.

35. Nation K, Snowling MJ: Semantic Processing and the Development of WordRecognition Skills: Evidence from Children with Reading Comprehension Difficulties. J. Mem. Lang. 1998, 39:85-101.

36. Stanovich KE: Toward an interactive-compensatory model of individual differences in the development of reading fluency. Read. Res. $Q$. 1980, 16:32-71.

37. Law JM, Wouters J, Ghesquiere P: Morphological Awareness and Its Role in Compensation in Adults with Dyslexia. Dyslexia 2015, 21:254-272.

*This study extended prior findings on the role of morphological awareness (MA) in 
individuals with RD by showing that university students with RD use MA as a compensatory mechanism. The authors discuss important implications for intervention strategies for those with RD using MA.

38. Quémart $\mathrm{P}$, Casalis $\mathrm{S}$ : Visual processing of derivational morphology in children with developmental dyslexia: Insights from masked priming. Appl. Psycholinguist. 2015, 36:345-376.

39. Traficante D, Marcolini S, Luci A, Zoccolotti P, Burani C: How do roots and suffixes influence reading of pseudowords: A study of young Italian readers with and without dyslexia. Lang. Cogn. Process. 2011, 26:777-793.

40. Cavalli E, Casalis S, El Ahmadi A, Zira M, Poracchia-George F, Colé P: Vocabulary skills are well developed in university students with dyslexia: Evidence from multiple case studies. Res. Dev. Disabil. 2016, 51:89-102.

41. Rose LT, Rouhani P: Influence of verbal working memory depends on vocabulary: Oral reading fluency in adolescents with dyslexia. Mind Brain Educ. 2012, 6:1-9.

42. Berninger VW, Abbott RD: Differences between children with dyslexia who are and are not gifted in verbal reasoning. Gift. Child $Q$. 2013, 57:223-233.

43. Van Viersen S, Kroesbergen EH, Slot EM, de Bree EH: High Reading Skills Mask Dyslexia in Gifted Children. J. Learn. Disabil. 2014, [no volume].

* This study utilizes a unique population - children who have dyslexia but are "gifted" - providing valuable perspective into the effects of compensation and masking in these children.

44. Cole P, Duncan LG, Blaye A: Cognitive flexibility predicts early reading skills. Front. Psychol. 2014, 5:1-8.

45. Diamond A: Executive Functions. Annu. Rev. Psychol. 2013, 64:135-168.

46. Hoeft F, McCandliss BD, Black JM, Gantman A, Zakerani N, Hulme C, Lyytinen H, Whitfield-Gabrieli S, Glover GH, Reiss AL, et al.: Neural systems predicting long-term outcome in dyslexia. Proc. Natl. Acad. Sci. U. S. A. 2011, 108:361-366.

47. Kiuru N, Lerkkanen M-K, Niemi P, Poskiparta E, Ahonen T, Poikkeus A-M, Nurmi $\mathrm{J}-\mathrm{E}$ : The role of reading disability risk and environmental protective factors in students' reading fluency in Grade 4. Read. Res. Q. 2013, 48:349-368.

48. Al-Yagon M, Margalit M: Social cognition of children and adolescents with LD: Intrapersonal and interpersonal perspectives. In Handbook of learning disabilities. Guilford Press; 2013:278-292.

49. Parhiala P, Torppa M, Eklund K, Aro T, Poikkeus A-M, Heikkilä R, Ahonen T: Psychosocial Functioning of Children with and without Dyslexia: A Follow-up 
Study from Ages Four to Nine. Dyslexia 2015, 21:197-211.

*Although several studies examine psychosocial functioning in children with dyslexia at schoolage, this study investigates psychosocial characteristics in the crucial period of transitioning to school. Moreover, the study evaluates how this social and emotional functioning changes over time after school entry, giving important clues to the relationship between internalizing/externalizing issues and RD.

50. Vaughn S, Elbaum B, Boardman AG: The social functioning of students with learning disabilities: Implications for inclusion. Exceptionality 2001, 9:47-65.

51. Willcutt EG, Pennington BF: Psychiatric comorbidity in children and adolescents with reading disability. J. Child Psychol. Psychiatry 2000, 41:10391048 .

52. Martínez RS, Semrud-Clikeman M: Emotional adjustment and school functioning of young adolescents with multiple versus single learning disabilities. J. Learn. Disabil. 2004, 37:411-420.

53. McNamara JK, Willoughby T, Chalmers H: Psychosocial status of adolescents with learning disabilities with and without comorbid attention deficit hyperactivity disorder. Learn. Disabil. Res. Pract. 2005, 20:234-244.

54. Bøe T, Øverland S, Lundervold AJ, Hysing M: Socioeconomic status and children's mental health: results from the Bergen Child Study. Soc. Psychiatry Psychiatr. Epidemiol. 2012, 47:1557-1566.

55. Raskind MH, Goldberg RJ, Higgins EL, Herman KL: Patterns of change and predictors of success in individuals with learning disabilities: Results from a twenty-year longitudinal study. Learn. Disabil. Res. Pract. 1999, 14:35-49.

56. Werner EE: Risk and resilience in individuals with learning disabilities: Lessons learned from the Kauai Longitudinal Study. Learn. Disabil. Res. Pract. 1993, [no volume].

57. Spekman NJ, Goldberg RJ, Herman KL: Learning disabled children grow up: A search for factors related to success in the young adult years. Learn. Disabil. Res. Pract. 1992, [no volume].

58. Firth N, Frydenberg E, Steeg C, Bond L: Coping Successfully with Dyslexia: An Initial Study of an Inclusive School-Based Resilience Programme. Dyslexia 2013, 19:113-130.

59. Al-Yagon M: Maternal Emotional Resources and Socio-Emotional Well-being of Children With and Without Learning Disabilities. Fam. Relat. 2010, 59:152169. 
60. Zheng C, Erickson AG, Kingston NM, Noonan PM: The relationship among selfdetermination, self-concept, and academic achievement for students with learning disabilities. J. Learn. Disabil. 2014, 47:462-474.

61. Gerber PJ, Ginsberg R, Reiff HB: Identifying alterable patterns in employment success for highly successful adults with learning disabilities. J. Learn. Disabil. 1992, 25:475-487.

62. Gerber PJ: The Impact of Learning Disabilities on Adulthood A Review of the Evidenced-Based Literature for Research and Practice in Adult Education. $J$. Learn. Disabil. 2012, 45:31-46.

63. Idan O, Margalit M: Socioemotional self-perceptions, family climate, and hopeful thinking among students with learning disabilities and typically achieving students from the same classes. J. Learn. Disabil. 2014, 47:136-152. ** This study addresses an important gap in literature that mainly focuses on deficits in children with LD by examining socio-emotional characteristics that may promote positive outcomes. Results show that hope mediated between risk and protective factors for these children, providing a suggested mechanism to enhance both academic competence and social functioning in this population.

64. Levi U, Einav M, Ziv O, Raskind I, Margalit M: Academic expectations and actual achievements: The roles of hope and effort. Eur. J. Psychol. Educ. 2014, 29:367-386.

65. Idan O, Margalit M: Hope theory in Education systems. Psychol. Hope 2013, [no volume].

66. Yeager DS, Dweck CS: Mindsets that promote resilience: When students believe that personal characteristics can be developed. Educ. Psychol. 2012, 47:302-314.

67. Aditomo A: Students' Response to Academic Setback:'Growth Mindset'as a Buffer Against Demotivation. Int. J. Educ. Psychol. 2015, 4:198-222.

68. Baird GL, Scott WD, Dearing E, Hamill SK: Cognitive self-regulation in youth with and without learning disabilities: Academic self-efficacy, theories of intelligence, learning vs. performance goal preferences, and effort attributions. J. Soc. Clin. Psychol. 2009, 28:881.

69. Schroder HS, Moran TP, Donnellan MB, Moser JS: Mindset induction effects on cognitive control: A neurobehavioral investigation. Biol. Psychol. 2014, 103:2737.

70. Singer E: Coping with academic failure, a study of Dutch children with dyslexia. Dyslexia 2008, 14:314-333. 
71. Terras MM, Thompson LC, Minnis H: Dyslexia and psycho-social functioning: an exploratory study of the role of self-esteem and understanding. Dyslexia 2009, 15:304-327.

72. Nalavany BA, Carawan LW: Perceived family support and self-esteem: The mediational role of emotional experience in Adults with Dyslexia. Dyslexia 2012, 18:58-74.

73. Al-Yagon M: Child-mother and child-father attachment security: Links to internalizing adjustment among children with learning disabilities. Child Psychiatry Hum. Dev. 2014, 45:119-131.

*Although previous research has examined the effect of parental support on the socio-emotional outcome of children with learning disabilities, this paper is unique in that it differentiates between maternal and paternal effects. Results suggest that mothers and fathers play unique roles in contributions to their child's internalizing difficulties.

74. Al-Yagon M: Perceived Close Relationships With Parents, Teachers, and Peers Predictors of Social, Emotional, and Behavioral Features in Adolescents With LD or Comorbid LD and ADHD. J. Learn. Disabil. 2016, [no volume].

**This study examines the impact of close relationships with parents, teachers, and peers on the socio-emotional and behavioral functioning of adolescents with LD, as well as those with comorbid LD/ADHD, compared to typically-developing controls. This population allows the author to examine potential impacts which are unique to students with LD.

75. Shany M, Wiener J, Assido M: Friendship predictors of global self-worth and domain-specific self-concepts in university students with and without learning disability. J. Learn. Disabil. 2012, [no volume].

76. Ahrens K, DuBois DL, Lozano P, Richardson LP: Naturally acquired mentoring relationships and young adult outcomes among adolescents with learning disabilities. Learn. Disabil. Res. Pract. 2010, 25:207-216.

77. Bowlby J: The making and breaking of affectional bonds. II. Some principles of psychotherapy. The fiftieth Maudsley Lecture. Br. J. Psychiatry 1977, 130:421431.

78. Lakey B, Cohen S: Social support theory and measurement. In Social support measurement and intervention: A guide for health and social scientists. 2000:29-52.

79. Dweck CS: Mindset: the new psychology of success. The Random House Publishing Group; 2006.

80. Heath N, Roberts E, Toste JR: Perceptions of academic performance: Positive illusions in adolescents with and without learning disabilities. J. Learn. Disabil. 2011, [no volume]. 
81. Karatsoreos IN, McEwen BS: Resilience and vulnerability: a neurobiological perspective. F1000 Prime Rep. 2013, 5.

82. Singh-Taylor A, Korosi A, Molet J, Gunn BG, Baram TZ: Synaptic rewiring of stress-sensitive neurons by early-life experience: A mechanism for resilience? Neurobiol. Stress 2015, 1:109-115. 


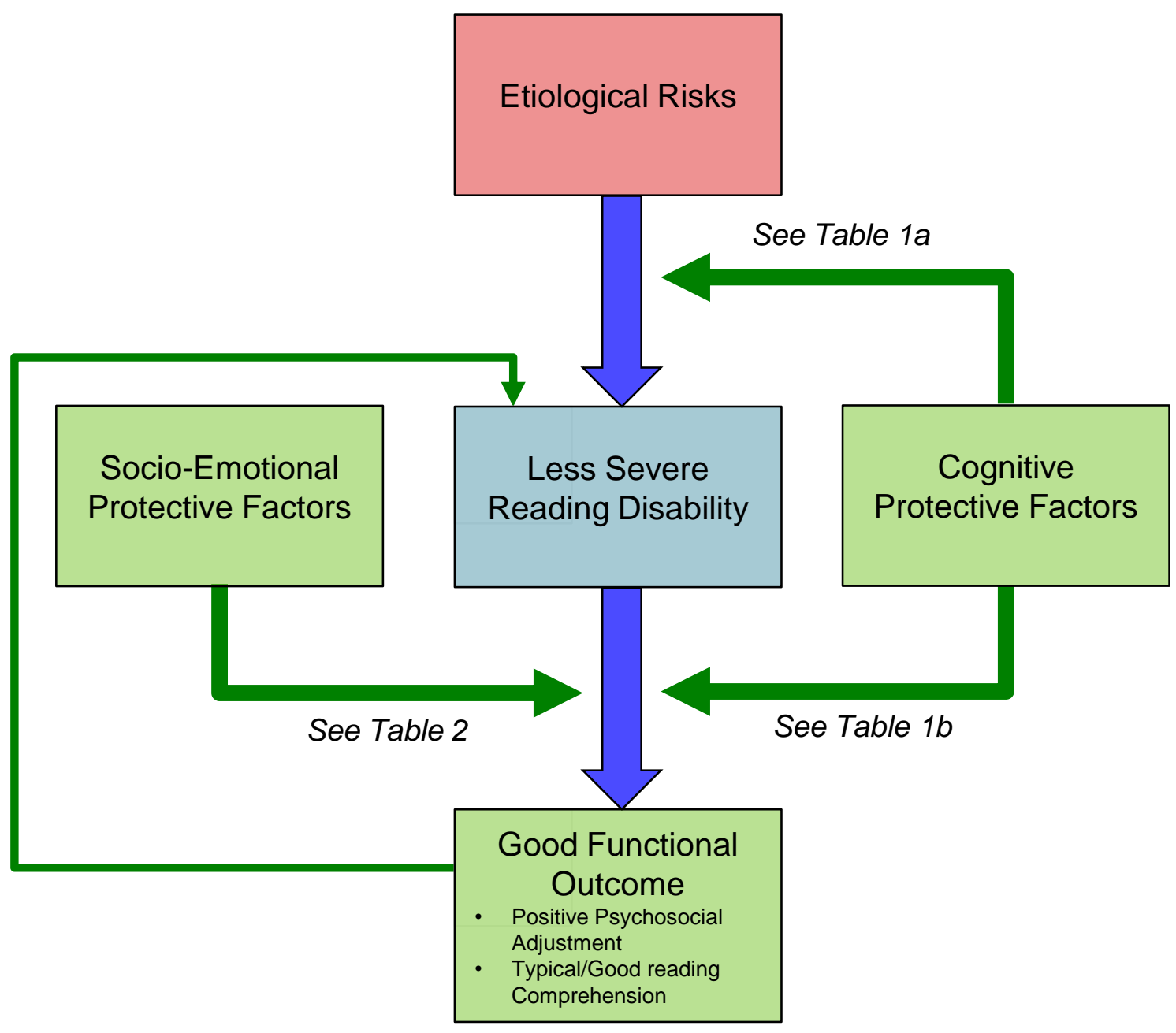

Figure 1. Interplay of etiological risks and protective factors in contributing to good functional outcome for those with RD when strong protective factors mediate outcome (thicker and solid green lines). The thinner green line indicates how good functional outcome may improve RD severity by enhanced reading experience for example, though more empirical research is needed in this area. Blue solid lines indicate trajectories of RD. 
Table 1a. Recent longitudinal studies (2009-2016) on potential protective factors contributing to cognitive resilience in pre-readers at-risk for RD.

\begin{tabular}{|c|c|c|c|c|}
\hline & Study & Classification of "At-Risk" & Relevant Findings & Protective Factor(s) \\
\hline \multirow{8}{*}{ 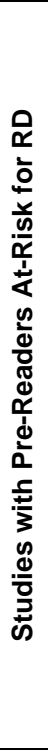 } & [26] & Family history of RD & $\begin{array}{l}\text { At-risk RD children in kindergarten with good reading outcome } 3 \text { years later showed lower } \\
\text { performance on spelling and reading accuracy than typical readers, but had better oral } \\
\text { language skills (expressive vocabulary) than at-risk RD children with poor reading outcome. }\end{array}$ & Oral Language Skills \\
\hline & [27] & $\begin{array}{l}\text { Family history of RD } \\
\text { Language difficulties }\end{array}$ & $\begin{array}{l}\text { Oral language measures (articulation, word repetition, and expressive vocabulary) in } \\
\text { preschool predicted phoneme awareness and grapheme-phoneme knowledge at school } \\
\text { entry, which predicted word-level literacy skills after school entry. }\end{array}$ & Oral Language Skills \\
\hline & [28] & Family history of RD & $\begin{array}{l}\text { At-risk RD children with no later RD outperformed at-risk RD children with later RD in grade } 2 \\
\text { on tasks of vocabulary production and maximum sentence length at } 1-2 \text { yrs old. }\end{array}$ & Oral Language Skills \\
\hline & [32] & Family history of RD & $\begin{array}{l}\text { Preschool fine motor skills predicted unique variance in early reading skills at age } 5 \\
\text { regardless of risk status. }\end{array}$ & Motor Skills \\
\hline & [31] & Family history of RD & $\begin{array}{l}\text { Irrespective of early cognitive risk factors, high levels of task-focused behavior were } \\
\text { associated with the absence of RD in grade } 2 \text { in kindergarteners at familial risk of RD at } 5 \\
\text { years old. }\end{array}$ & $\begin{array}{l}\text { High Levels of Task-Focused } \\
\text { Behavior }\end{array}$ \\
\hline & [30] & $\begin{array}{l}\text { Family history of RD } \\
\text { Language difficulties }\end{array}$ & $\begin{array}{l}\text { Executive function skills (inhibitory control, selective attention, working memory), fine motor } \\
\text { skills, and oral language skills (expressive/receptive vocabulary, sentence repetition, } \\
\text { sentence/word structure) in preschool all increase the prediction probability for later RD at } 8 \\
\text { years old. }\end{array}$ & $\begin{array}{l}\text { Executive Functions } \\
\text { Motor Skills } \\
\text { Oral Language Skills }\end{array}$ \\
\hline & [29] & Family history of RD & $\begin{array}{l}\text { In a longitudinal study, those at-risk pre-readers at } 3 \text { years who had the best reading outcome } \\
\text { at } 13 \text { years had strong oral language skills (non-word repetition, vocabulary, grammatical } \\
\text { sensitivity). }\end{array}$ & Oral Language Skills \\
\hline & [47] & $\begin{array}{l}\text { Low phonological awareness } \\
\text { and poor letter knowledge }\end{array}$ & $\begin{array}{l}\text { Environmental protective factors (peer acceptance, positive teacher affect) predicted } \\
\text { students' improved reading fluency in grade } 4 \text { with cumulative effects for those identified as } \\
\text { at-risk for RD in kindergarten. }\end{array}$ & Interpersonal Relationships \\
\hline
\end{tabular}

Table 1b. Recent studies (2009-2016) on potential protective factors contributing to cognitive resilience in those diagnosed with RD.

\begin{tabular}{|c|c|c|c|c|}
\hline & Study & Population & Relevant Findings & Protective Factor(s) \\
\hline \multirow{7}{*}{ 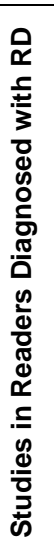 } & {$[37]$} & RD young adults & $\begin{array}{l}\text { Compensated readers (those with high literacy despite phonological deficits) performed } \\
\text { higher than their RD counterparts and similarly to controls on measures of morphological } \\
\text { awareness. }\end{array}$ & Morphological Awareness \\
\hline & [38] & RD children & $\begin{array}{l}\text { RD readers were assisted by semantic properties of morphemes, whereas typically } \\
\text { developing readers relied more on form properties of morphemes during a visual word } \\
\text { recognition task. }\end{array}$ & Morphological Awareness \\
\hline & [39] & RD children & $\begin{array}{l}\text { Both RD and typical children used morphemic constituents to improve their performance on a } \\
\text { pseudoword reading task. }\end{array}$ & Morphological Awareness \\
\hline & [40] & RD young adults & $\begin{array}{l}\text { The RD group outperformed controls in a vocabulary depth task, suggesting a potential } \\
\text { compensatory role for poor reading skills. }\end{array}$ & Vocabulary \\
\hline & [41] & RD adolescents & $\begin{array}{l}\text { In adolescents with RD, the impact of low verbal working memory on oral reading fluency } \\
\text { depended on vocabulary skills. }\end{array}$ & Vocabulary \\
\hline & [42] & RD children & $\begin{array}{l}\text { RD children with superior verbal reasoning significantly outperformed RD children with lower } \\
\text { verbal reasoning on reading, spelling, morphological, and syntactic skills }\end{array}$ & Verbal Reasoning \\
\hline & [43] & RD children & $\begin{array}{l}\text { Although gifted RD students still showed weaknesses in phonological awareness and rapid } \\
\text { naming compared to control groups, they showed strengths in working memory and language } \\
\text { skills compared to their non-gifted RD counterparts. }\end{array}$ & $\begin{array}{l}\text { Executive Functions } \\
\text { Vocabulary } \\
\text { Grammar }\end{array}$ \\
\hline
\end{tabular}


Table 2. A summary of the protective factors contributing to socio-emotional resilience for children with RD.

\begin{tabular}{|c|c|c|c|}
\hline & Study & Relevant Findings & Protective Factor(s) \\
\hline \multirow{5}{*}{ 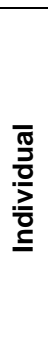 } & {$[68]^{*}$} & $\begin{array}{l}\text { The maladaptive effort attributions and self-regulatory profiles of youth with LD were due to their fixed mindset - } \\
\text { this suggests that adopting a growth mindset could lead to more positive cognitions when exerting effort in their } \\
\text { academics. }\end{array}$ & Growth Mindset \\
\hline & {$[63]^{*}$} & $\begin{array}{l}\text { In a structural equation model, hope mediated between risk and protective factors for high school students with LD, } \\
\text { contributing to greater academic self-efficacy. }\end{array}$ & Hopeful Thinking \\
\hline & {$[59]^{*}$} & $\begin{array}{l}\text { Children's sense of coherence (SOC) mediated the association between their maternal attachment and their hope } \\
\text { and effort. }\end{array}$ & Sense of Coherence \\
\hline & [58] & $\begin{array}{l}\text { A coping program for students with RD resulted in a more internal locus of control, which was associated with a } \\
\text { reduction in nonproductive coping strategies. }\end{array}$ & Internal Locus of Control \\
\hline & {$[60]^{*}$} & $\begin{array}{l}\text { In a sample of adolescents with LD, self-determination significantly correlated with self-concept and emerged as a } \\
\text { potential predictor of academic achievement. }\end{array}$ & Self Determination \\
\hline \multirow{4}{*}{ 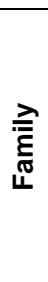 } & {$[63]^{*}$} & Family cohesion partially explained hopeful thinking among high school youth both with and without LD. & Family Cohesion \\
\hline & {$[59]^{*}$} & $\begin{array}{l}\text { A greater number of significant paths emerged between maternal affect and adjustment of children with LD than } \\
\text { those children without LD, suggesting that maternal emotion may play a unique role specifically for children with } \\
\text { LD. }\end{array}$ & Maternal Affect \\
\hline & {$[73]^{*}$} & $\begin{array}{l}\text { Maternal attachment relationships contributed to internalizing adjustment and paternal attachment to coping } \\
\text { resources for children with LD - these paths were more significant than in children without LD. }\end{array}$ & Strong Parental Attachment \\
\hline & {$[71]$} & $\begin{array}{l}\text { Children with RD who had strong parental relationships and parents with a greater understanding of RD had higher } \\
\text { global self-worth. }\end{array}$ & $\begin{array}{l}\text { Parental Support and } \\
\text { Understanding of RD }\end{array}$ \\
\hline \multirow{4}{*}{ 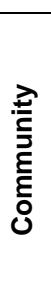 } & {$[75]^{*}$} & $\begin{array}{l}\text { University students with LD who had stable friendships were more likely to have higher global self-worth than } \\
\text { students with LD who did not have these relationships. }\end{array}$ & Peer Relationships \\
\hline & {$[74]^{*}$} & $\begin{array}{l}\text { For adolescents with LD (but not comorbid ADHD or typically developing students), ratings of their homeroom } \\
\text { teacher as caring and available contributed to high positive affect, and high quality of perceived friendship } \\
\text { contributed to lower internalizing and externalizing problems. }\end{array}$ & $\begin{array}{l}\text { Teacher Support } \\
\text { Peer Relationships }\end{array}$ \\
\hline & {$[76]^{*}$} & $\begin{array}{l}\text { Adolescents with LD who were mentored by teachers had higher self-esteem and graduation rates compared to } \\
\text { their non-mentored counterparts. }\end{array}$ & Mentorship by Teachers \\
\hline & [17] & $\begin{array}{l}\text { Teacher support protected children with RD from the negative impacts of peer rejection. Additionally, smaller class } \\
\text { size functioned as a protective factor against social withdrawal due to peer rejection. }\end{array}$ & $\begin{array}{l}\text { Teacher Support } \\
\text { Small Class Size }\end{array}$ \\
\hline
\end{tabular}

*The sample for these studies involved children with broad learning disabilities, which includes children with RD as well as disorders in mathematics and/or writing. 